Geograficando, vol. 13, n. ${ }^{\circ}$ 2, e026, diciembre 2017. ISSN 2346-898X

Universidad Nacional de La Plata.

Facultad de Humanidades y Ciencias de la Educación.

Departamento de Geografía

\title{
La territorialidad campesina indígena y la disputa por el territorio en el Chaco (Argentina)
}

\author{
Native peasant territoriality and dispute for the territory in Chaco \\ (Argentina)
}

\section{Julia Lucía Colla}

Consejo Nacional de Investigaciones Científicas y Técnicas (CONICET); Universidad Nacional del Litoral. Facultad de Humanidades y ciencias. Departamento de Sociología. Argentina | julialcolla@gmail.com

\section{PALABRAS CLAVE}

Campesinos

Indígenas

Territorio

Desarrollo capitalista

\section{KEYWORDS}

Peasants

Indigenes

Territory

Capitalist development

\section{RESUMEN}

El objetivo de este artículo es comprender la disputa por el territorio que mantienen los campesinos indígenas frente al capital en la provincia de Chaco (Argentina). Para ello, se reflexiona sobre la construcción de la territorialidad de estos sujetos y el papel que han ocupado en la expansión del desarrollo capitalista. Se trabaja con la comunidad del pueblo Qom que habita en los parajes rurales cercanos a la localidad de Pampa del indio, ya que allí se conformaron relaciones sociales distintas respecto a otros espacios geográficos y en cuanto a la vinculación entre indígenas, capital y territorio. El abordaje de la investigación es cualitativo, por lo que se ha recurrido a entrevistas en profundidad, observación participante (asambleas y acciones colectivas) y notas de campo. También se utilizaron datos catastrales, periodísticos y estadísticos que permitieron profundizar el análisis.

\section{ABSTRACT}

The aim of this article is to understand the territory dispute that the Indigenous peasants had been maintaining against the capital in the province of Chaco. To explain this I tried to reflect on the construction of the territoriality of these subjects and the role they have played during the growth of capitalism. I have worked with the Qom community who lives in the rural area near to Pampa del Indio town. I have chosen this village, regarding the different social relations that were formed there in comparison with other geographic spaces and the specific relationships between Indigenes, capital and territory. The approach of the research is qualitative, that is why I have resorted to deep Interviews, participative observation (assemblies and collective actions) and field notes. I also used cadastral and statistical data, which allowed me to make a deeper analysis. 


\section{Introducción}

El conflicto por el territorio ha cobrado un creciente auge en las últimas décadas, debido a un acelerado avance del desarrollo capitalista y la explotación de recursos naturales en lugares antes considerados como periféricos. Esto, de manera directa o indirecta, trastoca la vida de las poblaciones campesinas e indígenas que allí habitan y resisten.

En este artículo pretendemos comprender la disputa por el territorio que mantienen los campesinos indígenas frente al capital en la provincia de Chaco (Argentina). Para ello, se reflexiona sobre la construcción de la territorialidad de estos sujetos y el papel que han ocupado en la expansión del desarrollo capitalista.

Al respecto, concebimos el proceso histórico como un período de larga duración, en el que se manifiestan diferentes momentos en la relación entre indígenas, capital y territorio. Allí se generan “procesos constitutivos” concurrentes y divergentes, que se expresan en la forma en la que el capital se apropia de los espacios y en la que se desarrolla la resistencia campesina indígena (Zavaleta Mercado, 1986). En el espacio rural chaqueño, esto dio lugar a la conformación de dos territorios distintos: aquel organizado bajo la lógica de la acumulación de capital y otro donde el campesinado indígena lucha para su existencia (Fernandes Mançano, 2008). En esta línea, como construcción social, el territorio se concibe desde la apropiación material y simbólica del espacio habitado. Quienes viven allí, con historia y cultura compartida, producen “territorialización”, lo cual crea las condiciones para las identidades, “territorialidades”, que están inscritas en los procesos históricos mencionados (Porto Gonçalves, 2001).

Nuestra mirada está puesta en los parajes rurales de la localidad de Pampa del Indio, lugar donde las comunidades pertenecientes al pueblo Qom accedieron durante el siglo XX a condiciones de reproducción relativamente autónomas de su vida, generando procesos de campesinización, territorialización y desarrollo de una economía doméstica de subsistencia. No obstante, los cambios económicos y territoriales, ocurridos en la nueva etapa de expansión capitalista de los últimos veinte años, plantearon serias dificultades para la permanencia de este sector de la población rural chaqueña en esas condiciones de reproducción de su vida social. El choque de formas distintas de existencia frente a la nueva territorialidad del agronegocio -de exclusión, explotación y apropiación instrumental de la naturaleza-, ha convertido a esta zona en un lugar de fuertes disputas. Los campesinos indígenas han construido movimientos sociales y despliegan nuevas estrategias para la reproducción de su economía doméstica, en defensa del control y gestión de los recursos. Esto deja planteado el interrogante respecto de la manera en que estos sujetos defienden, con inferioridad de fuerzas, un tipo de territorialidad que se ha visto sensiblemente desarticulada en sus bases materiales por la apropiación de tierras y recursos por parte de grandes capitales y, además, respecto de cómo se contruye y defiende una nueva territorialidad, al calor de las luchas que encaran contra el avance de la lógica del capital en la zona.

De modo que, analíticamente, en este esquema se integran al menos tres territorialidades en conflicto: a) la experimentada por los campesinos indígenas durante el período algodonero iniciado en el tercer cuarto del siglo XX y que entró en crisis en los últimos veinte años; b) la que emerge actualmente de la hegemonía del capital en la zona y de la defensa precaria de su autonomía por parte de los movimientos campesinos indígenas; y c) la que constituye el horizonte de las luchas de 
los pueblos originarios, presente en sus programas reivindicativos y emergente en prácticas económicas y simbólicas a través de distintos tipos de experiencias.

\section{Metodología}

En línea con investigaciones previas (Colla, 2015), tomaremos como tema de estudio al pueblo Qom, que representa el 74,5\% de la población indígena de la provincia de Chaco ( 1 ) y es uno de los pueblos con mayor desplazamiento territorial y éxodo rural interno de la región del noroeste argentino (NEA). Particularmente, trabajaremos con la comunidad que habita los parajes rurales cercanos a la localidad de Pampa del Indio (2) (Figura 1), ya que allí se condensan muchos de los aspectos típicos de las disputas territoriales que nos proponemos estudiar.

Figura 1. Ubicación de Pampa del Indio, provincia de Chaco (Argentina)

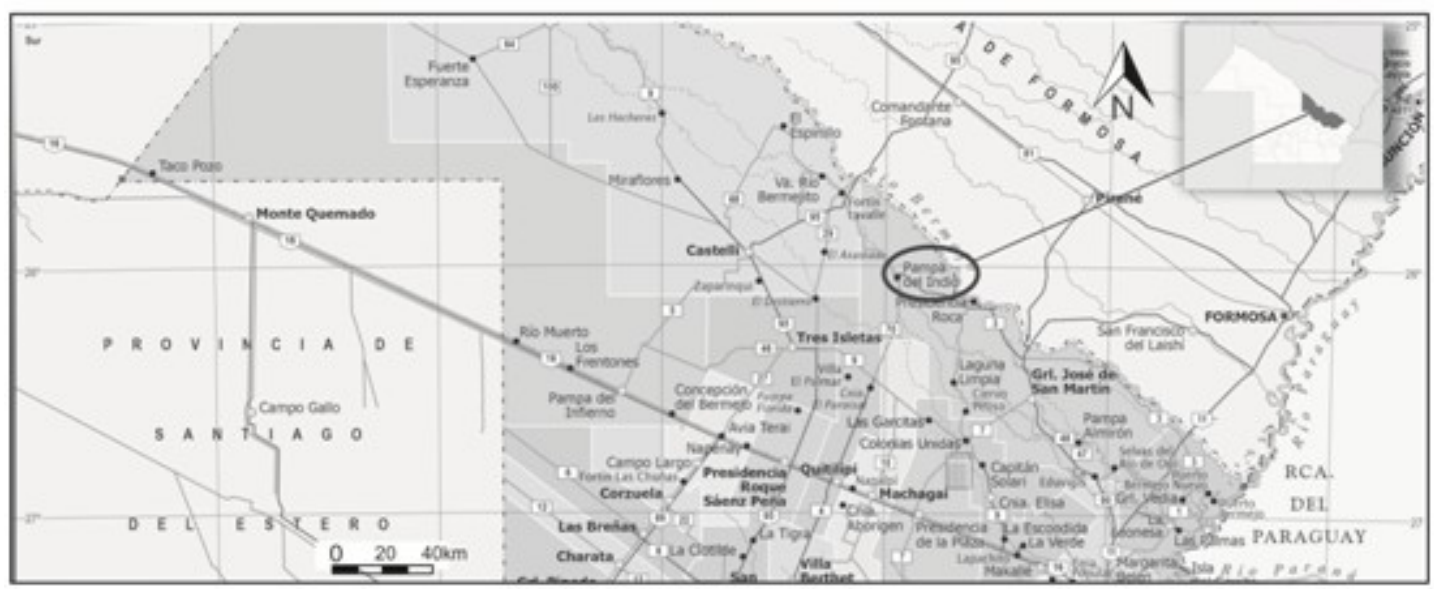

Fuente: Elaboración propia a partir de documentos del Instituto Geográfico Nacional.

El abordaje de nuestro trabajo es cualitativo: se ha recurrido a técnicas de recolección de información como entrevistas en profundidad, observación participante (asambleas y diversas acciones colectivas) y notas de campo que hemos realizado durante los últimos cuatro años de trabajo en la comunidad. También se utilizaron datos catastrales, periodísticos y estadísticos (Censos Nacionales, Encuesta complementaria a pueblos originarios, Relevamiento socioproductivo de la Federación Nacional Campesina) que permitieron profundizar el análisis.

\section{Resultados y discusión}

\section{Construcción de la territorialidad indígena en Pampa del Indio:}

Desde finales del siglo XIX la expansión geográfica desigual del desarrollo capitalista en el territorio chaqueño, y en cada ciclo de acumulación por desposesión (프), planteó una configuración particular en cuanto a la formación económica-social (Harvey, 2005). Sobre todo, respecto al espacio geográfico alcanzado a través del despojo y la puesta en producción capitalista (vinculada a las actividades económicas y la apropiación y valorización de tierras) y a la subordinación a la dinámica económica que impuso el Estado hacia los pueblos indígenas preexistentes. Esto reconfiguró a los sujetos, sus territorios y planteó la yuxtaposición de distintas territorialidades. 
Sobre esto, el Estado nacional implementó, durante todo el siglo XX, diferentes instrumentos de concentración, sedentarización y disciplinamiento de la fuerza de trabajo aborigen (Musante, 2009; Iñigo Carrera, 2009). Estas políticas estuvieron caracterizadas por las configuraciones de sentido impresas al indígena que, en cada momento, facilitaron u obstaculizaron la relación del Estado nacional, provincial y pueblos originarios. Entre estos mecanismos, destacamos la disposición de tierras fiscales para el asentamiento de indígenas bajo las denominadas “Reservas” (뜨).

Fernández y Braunstein (2001) analizan cómo hacia el año 1918 la comunidad Qom, liderada por el Cacique Taigoyi, fue contratada para trabajar en el Ingenio Las Palmas. La necesidad de mano de obra temporal para el obraje, y el asentamiento en las cercanías para facilitar el regreso temporal al Ingenio, derivaron en gestiones para el acceso a la tierra. Producto de negociaciones entre el Cacique y el presidente Hipólito Yrigoyen en Buenos Aires, se obtuvo el compromiso de otorgamiento de veinte mil hectáreas bajo la imagen de "Reserva Aborigen” (므). Estas tierras formaban parte de la Colonia Pastoril Rodríguez Peña, de unas 440 mil hectáreas, fundada a través del mismo decreto que creó la Colonia Teuco, en 1921. Ubicados entre los actuales departamentos de General Güemes y Libertador General San Martin, estos territorios no estaban destinados solamente a pueblos originarios, sino también al asentamiento de campesinos pobres (“criollos”) (6). Como su nombre lo indica, se "reservaban” tierras fiscales para proyectar en un futuro el trazado de las colonias. Esto implicó para los pueblos originarios una territorialización particular ya que, a diferencia de las "Reducciones estatales indígenas" (ㅁ), que funcionaron como sistema de concentración de personas para la "pacificación del indio" y su disciplinamiento en el trabajo en condiciones de explotación y semiesclavitud, podrían ser apropiados como espacios "libres”, por fuera del control disciplinador de éstas últimas.

Según Trinchero (2000), en estos territorios el trabajo de reproducción de las familias indígenas durante los meses en que estos no eran incorporados al proceso productivo capitalista, era pagado por la economía doméstica basada en la recolección, la pesca, la marisca y una incipiente agricultura en un contexto de posibilidades de acceder a la tierra. Esto dio lugar a un proceso desigual de campesinización de estos pueblos, que funcionó también como estrategia de subordinación al capital y como reservorio de mano de obra compuesta de sujetos “civilizados” y subordinados a la intervención estatal. Más aún, su dominación y explotación produjo nuevas identidades basadas en el complejo raza/etnia, que tuvieron un fuerte componente de segregación y división territorial y se convirtieron en fundamento de una cultura de racismo y etnicismo que aún persiste (Quijano, 2014). En este sentido, la diferenciación étnica como fundamento “natural” de la explotación y relación de poder significó “la disposición de indios” para el trabajo de temporada y en ubicaciones territoriales estratégicas, como lo fueron las Reservas indígenas.

La colonia agrícola que daría lugar a la fundación de Pampa del Indio data de 1928. Posteriormente, la reterritorialización de la población indígena se definió sobre parcelas individuales, transformando la organización y el uso social colectivo del espacio. Más tarde, en 1946, el gobierno de Juan D. Perón creó la colonia Campo Medina, a unos 30 km de Pampa del Indio, a partir de la expropiación de un campo de 3000 hectáreas perteneciente a Pablo Medina.

Luego, tras las gestiones realizadas por el cacique y pastor evangélico Pedro Martínez (ㅁ), quien fue sucesor de Taigoyi, las familias accedieron a permisos de ocupación en lotes de 100 hectáreas y 
fraccionadas en parcelas de 25 hectáreas por unidad familiar. Al mismo tiempo, se fundó una Escuela de educación primaria en el paraje rural de Pampa Grande, y se entregaron herramientas e insumos para desarrollar la producción familiar de algodón que se comercializaba a través de cooperativas. Tierra, educación y producción agraria se convertirían, de ese modo y en ese contexto especial, en mecanismos de subordinación al capital y a sus pautas culturales, y funcionarían como estrategias para contener y absorber de manera subalterna a estos sujetos dentro del conjunto mayor de la "sociedad nacional” (모). En este sentido, la construcción de una identidad etnopolítica (Vázquez, 2000) de los campesinos indígenas vinculada a la territorialidad de la comunidad, estuvo fuertemente anclada en la reorganización del espacio impuesta por el capital para la producción agraria, y bajo los parámetros institucionales e ideológicos del Estado-nación. Pero también, la existencia de territorios menos permeados por el capital (por ejemplo, el monte) permitía cierta independencia de estos grupos para crear nuevas (otras) formas de territorialidad y resistir el proceso colonizador. Incluso, la disputa por el uso del espacio y de la naturaleza se dio bajo mecanismos más velados y anclados en las relaciones de reciprocidad y las prácticas de resistencia étnica, como la marisca, la recolección de frutos y miel y la artesanía, prácticas que se producían en la territorialidad indígena y por fuera de los límites parcelarios. De ahí que en la memoria colectiva de la comunidad indígena estas experiencias vinculen la producción familiar propia, el trabajo extrapredial temporal (que realizaban en el Ingenio, en la carpida y cosecha de algodón en explotaciones vecinas), y la solidaridad entre las familias, como una época de relativo bienestar. Ciertamente, en estas narrativas quedan solapadas las condiciones materiales de explotación que este tipo de producción suponía, o la discriminación que sufrían las familias al momento de negociar un precio justo por la producción de algodón. Sucede que el valor subjetivo de ese pasado aumenta en la medida en que la territorialidad de este nuevo ciclo de expansión capitalista no los absorbe de manera subordinada, como entonces, sino que los excluye y los priva de las condiciones materiales mínimas, para que puedan desarrollar su subsistencia de un modo más autónomo, aunque fuera una parte del año.

En síntesis, estas experiencias se convierten en lugares de producción de territorialidades y de sujetos, que se rememoran en las narrativas y que también fundamentan prácticas y discursos etnopolíticos divergentes dentro del mundo indígena respecto a la recuperación del monte y la producción agraria, y sobre todo, a los sentidos impresos a la tierra y el territorio. En consecuencia, se configura una matriz identitaria particular y la construcción político-ideológica expresada como procesos de etnicidad (Vázquez, 2000) entre quienes se autoadscriben como campesinos indígenas y participan actualmente en el movimiento social Federación Nacional Campesina (FNC). De aquí también que el eje del conflicto por el control del espacio se transformara en una disputa por las diferentes lógicas de relacionarse con la naturaleza, de apropiarse de los bienes naturales y de producir alimentos.

\section{2. "Del otro lado": campesinos indígenas frente a las fronteras del capital}

En las últimas dos décadas, se asiste a la inauguración de un nuevo ciclo del capitalismo que reemplazó la matriz agrícola del Chaco, basada en el cultivo de algodón, los ingenios azucareros y la actividad maderera. Esta expansión encontró su motor primordial en inversiones de capital para 
la producción a gran escala de soja, maíz y trigo -entre otros cultivos- y el avance de megaproyectos extractivistas de madera, minería e hidrocarburos. También surgieron mecanismos de acumulación por desposesión, particularmente en relación a la apropiación del espacio y la relación con la naturaleza (Harvey, 2005). En efecto, se evidencia una mayor concentración de la propiedad de la tierra, la ampliación de la superficie productiva y la aparición de nuevos actores sociales vinculados con el capital extranjero, e incluso del Estado, quien ha participado como mediador para adjudicaciones de tierra fiscal y de determinadas operaciones de capital (por ejemplo, el convenio en el año 2010 entre el gobierno provincial y el proyecto de la Corporación Al-Khorayef -Arabia Saudita- para explotar la zona de El Impenetrable).

Esto va acompañado de un proceso de mercantilización de la naturaleza y la intensificación de los niveles de violencia, generadas en torno a las disputas geopolíticas por el control y apropiación de estos recursos, y por la utilización de tecnologías extractivas cada vez más gravosas para los ecosistemas (Machado Aráoz, 2015). Como parte de este proceso, se expulsa a la población rural y se desterritorializa a las comunidades indígenas y campesinas (Brodersohn, Valenzuela y Slutzky, 2009; Giarracca y Teubal, 2005).

En este contexto, en los parajes rurales de Pampa del Indio, los conflictos que se generan entre los representantes del capital y las comunidades de campesinos indígenas Qom expresan no sólo una disputa entre actores sino entre dos lógicas territoriales: aquella impartida por el agronegocio para la acumulación de capital, y aquella que surge en la lucha del campesinado por organizar el territorio para su existencia (Mançano Fernandes, 2008).

Desde la década de 1990, un amplio sector de campesinos (indígenas y no indígenas) encontraron serias dificultades para adecuarse a los cambios de restructuración productiva, principalmente, por las dimensiones de las explotaciones y la deficiente infraestructura tecnológica. Asimismo, entre los campesinos indígenas, para quienes tenían una producción algodonera de baja escala, realizaban trabajo temporal extrapredial en la carpida y cosecha de algodón en explotaciones aledañas, estas condiciones se agravaron por la disminución de la rentabilidad del cultivo, el reemplazo de su trabajo manual por la mecanización y por la reconversión a la ganadería de sus vecinos. En el marco general de desintegración de las economías regionales, esto se tradujo en la falta de oportunidades para generar alternativas productivas o comerciales y en la obstrucción de otras modalidades de intercambio (Balazote, 2012). Como resultado, se pasó de una dinámica de inclusión subordinada vía explotación estacional y reproducción incompleta de la vida independiente- a otra de exclusión absoluta del nuevo sistema productivo (Valenzuela y Scavo, 2009).

Paralelamente, la nueva dinámica de acumulación por desposesión generó que las comunidades indígenas fueran literalmente “cercadas” por grandes latifundios para la valorización de la tierra y confinadas a la exclusión y a la desterritorialización de sus espacios de reproducción de vida, expresión de su historia e identidad cultural y espiritual. Actualmente, por ejemplo, los parajes rurales de Pampa del Indio (Campo Medina, Lote 4, Campo Nuevo, entre otros) limitan con grandes propiedades. Una de estas estancias fue, hasta la década de 1970, propiedad de la empresa COMEGA S.A, vinculada al grupo Bunge \& Born, que se había apropiado de esas tierras luego de la campaña militar de 1884 . Hoy día, corresponde a la estancia La Leonor y abarca 30 mil hectáreas entre la ruta provincial №3 y el río Bermejo. También se encuentra la Estancia Don Panos, de 42 
mil hectáreas, que pertenece a Unitec Agro S.A., un emprendimiento agropecuario iniciado en 1995 por el grupo encabezado por el empresario Eduardo Eurnekian. El mismo cuenta con laboratorios de genética avanzada, maquinaria de siembra directa, y uso de riego mecanizado, entre otras tecnologías de última generación (10).

Este escenario modificó el mapa de la zona y dividió el espacio social bajo dos formas divergentes y contrapuestas que se disputan el control y la construcción de determinado territorio: el producido bajo la lógica del capital para la valorización de mercancías, y el “vivido” y apropiado por las comunidades campesinas indígenas para la reproducción de la vida, que comprende el uso del monte y la producción de subsistencia. No obstante, estas relaciones sociales no plantean una diyuntiva solamente en el plano espacial y físico, sino también bajo formas simbólicas, más veladas y con distintos grados de violencia. Además, las prácticas de resistencia que generan las poblaciones desposeídas son, en ocasiones, resignificadas bajo determinadas lógicas del capital en las cuales se imprimen nuevos sentidos al territorio.

En primer lugar, los representantes del capital (esto contempla a los grandes latifundios como así también a actores subalternos, como los productores de escala media ligados actualmente a la ganadería) instrumentan acciones legales para el acaparamiento de tierras indígenas, aprovechándose de la inestabilidad jurídica que tienen los títulos de propiedad o los procesos políticos de resarcimiento histórico. Si bien, desde la década de 1980, en la zona de estudio se han implementado políticas públicas desde el Instituto de Colonización para la titularización de tierras indígenas, las demandas de las comunidades para la regularización de títulos comunitarios, de tenencia precaria (11) o de reconocimiento de territorio, se someten a un proceso de burocratización que se enfrenta a la velocidad con la que avanza la privatización de las tierras y los megaemprendimientos en la región. En efecto, estas reparaciones plantean un reconocimiento discursivo por parte de los diferentes gobiernos provinciales sobre los derechos indígenas, pero no tienen la misma respuesta en el plano material (Musante, 2009).

En segundo lugar, la desposesión sucede bajo formas de una profunda violencia simbólica sobre el pueblo Qom (Wright, 2009). Particularmente cuando la privatización del monte avanza sobre los espacios que la comunidadad destinaba para sus prácticas de marisca y recolección, e incluso sus ritos religiosos y ceremoniales (como el caso del cercamiento de los cementerios aborígenes localizados dentro de la Estancia Don Panos, y en determinados lotes aledaños). Esta situación conduce a los sujetos a implementar nuevas estrategias para continuar con sus prácticas de reproducción social, que en algunos casos se resignifican bajo la lógica del capital. Esto se traduce en el trabajo asalariado extrapredial (principalmente temporal: “changas”); la comercialización de sus artesanías; la utilización de los recursos económicos de la asistencia estatal para cubrir gastos mínimos de subsistencia familiar (Asignación Universal por Hijo, pensiones por discapacidad, etc.); el aprovechamiento de insumos para la producción que brindan determinados organismos estatales (como el INTA), y el despliegue de estrategias colectivas para la produccion de alimentos, como los actuales proyectos de semilleros comunitarios (de maíz y mandioca) que podrían funcionar como repositorios de insumos para futuras cosechas.

En tercer lugar, si bien se han localizado situaciones particulares de arrendamiento de tierras a campesinos indígenas por parte de productores ganaderos de escala media, grandes terratenientes y 
asociaciones civiles patronales, como la Sociedad Rural Argentina (SRA), predominan modos extraeconómicos de apropiación de la tierra por el capital. Estas acciones plantean mecanismos de acumulación por desposesión que no necesariamente responden a las lógicas operadas en otros espacios geográficos más consolidados del capital, como sucede -por caso- en la zona pampeana, donde son los mecanismos más sutiles del mercado los que ordenan el reparto de tierras y la explotación del trabajo. Pero a la vez, como contracara, las estrategias para el acceso y control de los espacios que emplean las comunidades indígenas tampoco se basan en un consenso social alrededor del valor de la propiedad privada, o el mercado, sino que son operadas bajo otras formas y con otros objetivos a traves de las tomas de tierras, más bien como resarcimiento histórico que con fines de valorización de mercancías y acumulación de capital. Estas estrategias emergentes de acceso a los recursos tensionan las distintas territorialidades en disputa y plantean nuevas reglas de juego en el conflicto territorial con el capital y el Estado. En este escenario, los campesinos indígenas despliegan los recursos legales conseguidos en luchas etnopolíticas previas (como la Ley 26.160, que impide todo acto procesal que plantee el desalojo o desocupación de las tierras habitadas por comunidades). Aquí el Estado aparece, según los contextos particulares, bajo una doble racionalidad: garantizando los derechos o restringiéndolos, ordenando los desalojos generalmente de manera violenta y con represión- (como sucedió en 2011 con la toma de tierras en el predio ubicado en el Paraje rural de El Rincón de Pampa del Indio) (Cecchi, Horacio, 2006).

En cuarto lugar, en estos territorios también se desarrolla una disputa por el tipo de relación que se establece con la naturaleza. El proceso de mercantilización de la misma -consolidado en este nuevo ciclo de expansión del capital- ha provocado profundos daños a los ecosistemas y a los pobladores, cercenando las condiciones para la reproducción autónoma de las comunidades (Machado Aráoz, 2015). Desde la puesta en funcionamiento de la Empresa Don Panos, por ejemplo, se violó sistemáticamente la legislación existente para la preservación medioambiental, y se sometió a los trabajadores a condiciones de extrema insalubridad. Por la utilización de agrotóxicos y la contaminación del agua, el suelo y el aire, se realizaron reiteradas denuncias, entre ellas las que se hicieron por la muerte de pobladores y la cantidad de abortos y recién nacidos con anomalías congénitas que se registraban en el Hospital de la zona. Según un estudio de 1996, sobre cien trabajadores, treinta y dos tuvieron secuelas clínicas (Klipphan y Enz, 2006). En aquel momento, los pobladores denunciaban:

Nos sentamos a cinco metros del alambrado que nos separa de Don Panos, desde donde llegaban las fumigaciones (...) Teníamos naranjos, mandioca. Todo se secó por el veneno. Las 26 chivas madres que tenía murieron. Enterré 15 gallinas. Se morían las abejas, que cuidaba uno de mis hijos, que al final terminó cansado y yéndose a la ciudad, a vivir de hacer changas (Revista La Vaca N²92, 2015)

Además, las obras de canalización realizadas de los ríos Bermejo y Guaycurú para riego artificial y con la intención de controlar los desbordes naturales de los afluentes, provocaron una profunda sequía y falta de irrigación de los suelos de las explotaciones aledañas, en las que viven los campesinos originarios. La falta de agua de un lado del alambrado y los campos verdes del otro, graficaban este paisaje desigual. No obstante, en el año 2012 la Justicia de la provincia de Chaco sancionó una medida cautelar contra Don Panos para restringir las fumigaciones en la zona, la cual 
actualmente se destina a ganadería (12).

Todas estas limitaciones señaladas fueron generando el desplazamiento de las poblaciones a porciones cada vez más pequeñas de territorio, profundizando el “arrinconamiento" de las comunidades y cercenando las posibilidades productivas en el acceso a los medios de producción. El mapa catastral del Departamento Libertador General San Martín (Figura 2) permite graficar la línea divisoria de los lotes pertenecientes a las familias campesinas y el cercado de grandes latifundios. La referenciación en el mismo se realizó a partir de un relevamiento territorial con entrevistas a los pobladores.

Figura 2. Mapa Catastral del Departamento Lib. Gral. San Martín.

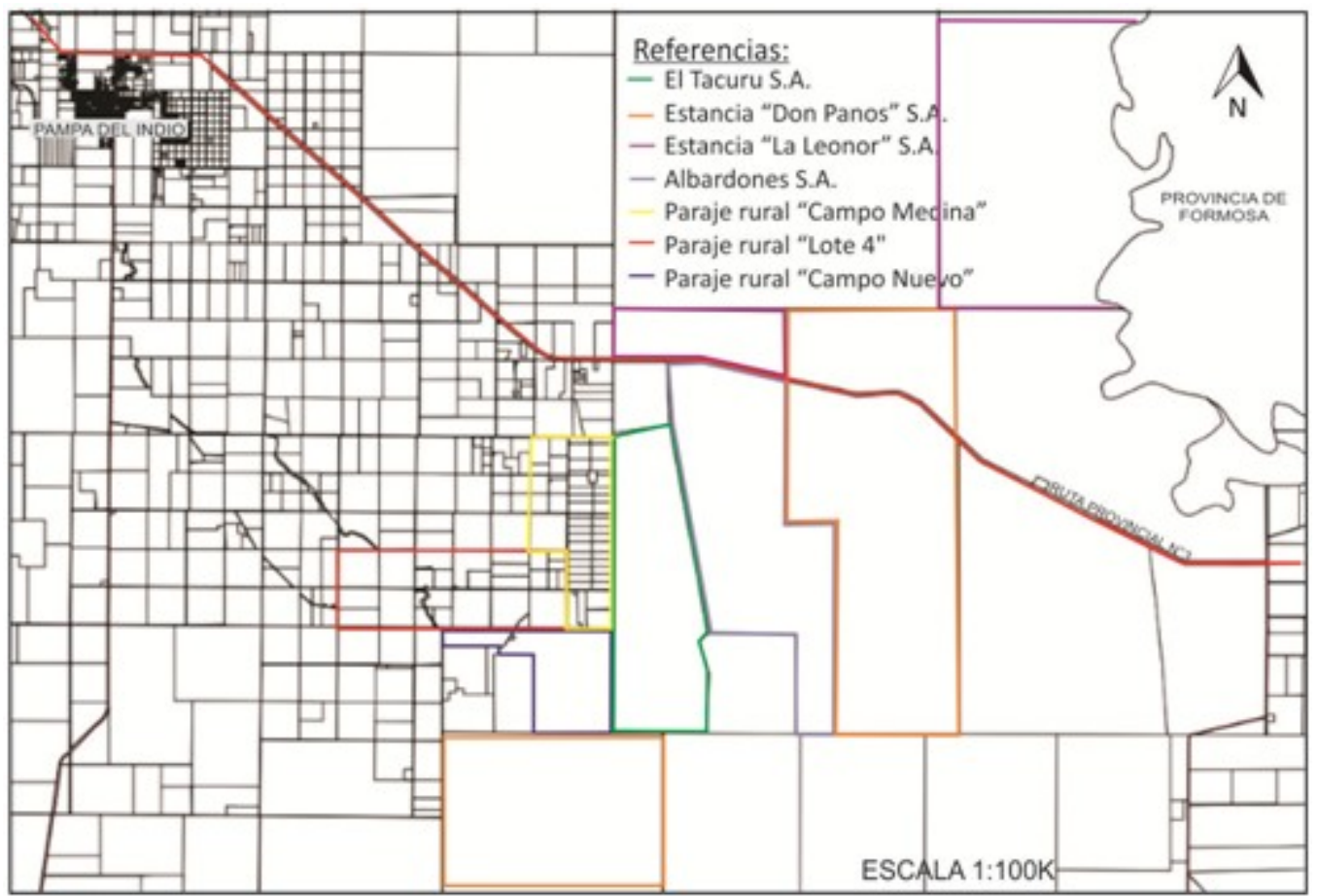

Fuente: Elaboración propia a partir de datos de la Dirección Provincial de Catastro y Cartografía de la Provincia de Chaco. Departamento Sistemas de Información.

Sumado a esto, en los años 2008 y 2014, las organizaciones campesinas y de pueblos originarios realizaron relevamientos de tierra y condiciones de vida en la zona. Los resultados parciales arrojaron que en 1824 hectáreas censadas en los parajes rurales habitan 1480 pobladores. Esto resulta un promedio de 1,23 hectáreas por habitante ( $\underline{13})$. En relación a la calidad de vida de las unidades domésticas, el $64,5 \%$ de la población vive en condiciones habitacionales adversas (vivienda de adobe y hacinamiento), con graves dificultades sanitarias (escasez de recursos para mantener en condiciones los reservorios de agua), y sobre un total de 130 familias relevadas, sólo el 10,6\% declaró tener ingreso por trabajo temporal extrapredial (“changas”). El ingreso predominante de la población es el beneficio social de la Asignación Universal por Hijo (AUH), la cual no es utilizada solamente para cubrir gastos de los menores, ya que en sólo cuatro casos es compartido con otro tipo de ingreso económico (14).

En definitiva, en los nuevos escenarios agroalimentarios se generan relaciones profundamente 
desiguales. Por un lado, entre quienes se pueden transformar e integrar a las nuevas dinámicas de acumulación y aquellos que controlan y concentran la propiedad. Por otro lado, quienes se ven relegados o excluidos al corto plazo de los grandes círculos productivos, con pocas posibilidades de desarrollar una producción agropecuaria, incluso para autoconsumo. Entre ellos, las poblaciones de campesinos indígenas cuya subsistencia depende de la tierra, concebida no sólo como bien material, sino como expresión de su historia e identidad cultural y espiritual. En consecuencia, en estos escenarios la lucha por la tierra, lejos de acabarse, se produce entre actores cada vez más desiguales.

\section{3. "Ni uno más se va del campo": el campesinado como horizonte político}

La creciente presión campesina sobre la tierra frente al avance del latifundio deja planteado que no se trata de un proceso sustentado en una única racionalidad. En efecto, los usos del territorio son un problema constante y dinámico, puesto que los actores sociales entablan luchas y alianzas de forma permanente para imponer su visión de cómo organizarlos (Fernandes Mançano, 2008).

Desde esta perspectiva, consideramos que el campesinado indígena chaqueño muestra en sus resistencias y estrategias de reproducción la vitalidad de un sujeto social específico y definido. Estos accionan para hacer frente a las condiciones desfavorables que parecen reforzar las tendencias descampesinistas del desarrollo del capitalismo en el agro. De aquí la consigna de la FNC: “Ni uno más se va del campo”, haciendo referencia al éxodo de población rural (Colla, 2015).

En relación con esto último, la afirmación identitaria de estos sujetos como "campesinos originarios” es un posicionamiento político que no hace más que disputar el “cómo”, "para qué” y para “quiénes” del espacio apropiado. Además, esta mirada considera el territorio como un medio de vida desde una concepción particular y con reivindicaciones específicas como pueblos originarios. Para ellos, la tierra "no tiene fronteras fijas” en términos de propiedad (desde la concepción liberal moderna). Son espacios de apropiación efectiva mediante prácticas culturales, agrícolas y políticas (Escobar, 2015; Porto Gonçalves, 2009). Tal como dice un dirigente Qom:

No queremos hablar de tierra, eso son sólo $30 \mathrm{~cm}$ debajo de nuestros pies. Nosotros tenemos que exigir territorio (...) El mundo indígena no tiene fronteras, los blancos nos hicieron los límites. El territorio no son las 3 hectáreas que tenemos. El territorio es nuestra vida. $(\underline{15})$

Esto también presenta el desafío de reflexionar sobre que el ethos de estos pueblos sigue siendo la colectividad (y no el individuo), y que tienen la plasticidad de mudar de estrategias conforme evolucionan las condiciones que le impone el capital (Bartra, 2011). Entre ellas, el aprovechamiento de los lazos de reciprocidad y parentesco, y de los recursos legales disponibles para pueblos originarios.

En esta línea, los campesinos originarios que integran la FNC en Pampa del Indio vienen planteando otros mecanismos de recuperación y apropiación del espacio, como lo son la toma de tierras, la construcción de viviendas rurales y la lucha política por redimir las prácticas agrícolas y culturales. El objetivo es la recuperación del territorio y el fortalecimiento de las economías domésticas que permitan enfrentar la situación de extrema pobreza de la población, como así 
también reconfigurar las economías locales. A modo de ejemplo, la toma de 1000 hectáreas de tierra en el paraje rural de El Rincón en 2011 que mencionamos anteriormente, y el acceso a la adjudicación de 415 hectáreas posterior al conflicto; el centenar de viviendas rurales que edificaron los campesinos en colaboración con un equipo de arquitectos y profesionales, viviendas que contribuyeron a mejorar las condiciones habitacionales de la población; la producción de algodón con comercialización comunitaria durante los planes 2009 y 2011 (16) (que se efectivizaron luego de determinadas acciones colectivas como los cortes de ruta y la llamada "Marcha del Impenetrable”), entre otras.

Estos acontecimientos no sólo ponen en evidencia el conflicto por la tierra y la instrumentación por parte de los indígenas de recursos legales existentes, sino que también son experiencias que enfrentan la lógica de desposesión impuesta por el capital y tensionan las territorialidades construidas en esos espacios a través de estrategias de resistencia. Estas prácticas se vuelven clave para torcer los dispositivos de poder y encontrar condiciones para permanecer en el campo como campesinos indígenas.

\section{Conclusiones}

En este artículo reflexionamos acerca de la construcción territorial de los campesinos originarios de Pampa del Indio y su influencia en la conformación de identidades específicas.

En esta localidad, a mediados de siglo XX, la presencia estatal reordenó el territorio indígena nucleado en las Reservas y subsumió a los sujetos a la producción agropecuaria por la vía mercantil y la explotación estacional de la fuerza de trabajo, construyendo relaciones sociales distintas a otros espacios geográficos. La relación que mantuvieron los campesinos indígenas con el capital dio cuenta del grado de autonomía relativa que conservaron para poder crear otras formas de reproducción social, por caminos alternativos de cooperación y reciprocidad. Aunque, a su vez, el carácter relativo de esa autonomía ayuda a explicar las dificultades estructurales y políticas que estos sujetos enfrentan para luchar por el territorio y llevar a cabo proyectos productivos colectivos y alternativos a la lógica de acumulación y apropiación de la tierra por el agronegocio.

No obstante, como reflexión final, creemos que en estas comunidades un indicador de la vitalidad social del campesinado originario en la disputa por el territorio se manifiesta en la ocupación de tierras y en las demandas como productores directos. Sea como iniciativa familiar o como accionar de las organizaciones, no dejan de plantearse estrategias de resistencia, y pasan a recrearse nuevas territorialidades frente a la acumulación por desposesión que impone el capital. Al respecto, consideramos que la creciente presión sobre la tierra y la producción, sea desde aquellos que carecen totalmente de ella, o de aquellos que por diversos motivos requieren superficies mayores, generan la recreación campesina como sujeto político, dispuesto a disputar la tierra no sólo como medio de producción, sino como territorio integral de su ser-en-el-mundo (Wright, 2008).

\section{Notas}

1. El 3,9\% de la población de la provincia del Chaco se reconoce indígena (superando la media 
nacional de 2,4\%). De esto, el 74,5\% se autoreconoció perteneciente al pueblo Qom, el 11,2\% al Wichí y el 9,4\% al Mocoví (Fuente: Instituto Nacional de Estadística y Censos).

2. Pampa del Indio es una localidad que se encuentra en el Departamento General San Martín, en el extremo norte de la Provincia de Chaco y a unos 220Km de la capital, Resistencia.

3. David Harvey recupera el concepto de acumulación originaria de Karl Marx y lo utiliza no sólo para aludir al momento fundacional de formación del capitalismo, sino más bien para describir un proceso de larga duración en el que el despojo es la característica principal que vincula las actividades económicas y la apropiación de tierras. Entre esos aspectos, se destacan la expulsión violenta de habitantes del campo; la transformación de los derechos comunes, colectivos y públicos en derechos privados y el abandono de la idea de propiedad común; la conversión de la fuerza de trabajo en mercancía y la eliminación de todas las formas de producción y consumo no mercantiles (Harvey, 2005).

4. Esta modalidad de entrega de tierras a comunidades indígenas funcionó hasta la sanción de la Constitución de 1994, en la que se promovió la titularización comunitaria para las tierras entregadas en Reserva (Fuente: Constitución de la Provincia del Chaco-Art.37). No obstante, previa a la legislación, muchos de esos territorios fueron absorbidos por ejidos municipales, el asentamiento de criollos, entre otros.

$\underline{5}$. Aunque no se cuenta con los decretos oficiales que aseguren esta información, documentos históricos avalan la información. Por ejemplo, una notificación firmada por el secretario de la Gobernación dirigida al jefe de policía del Chaco fechada en mayo de 1932, informando de la puesta en "posesión precaria" "de 20.000 hectáreas en Pampa del Indio a la tribu del cacique Taigoyic (Fuente: Archivo histórico de la Provincia de Chaco).

6. Mayormente eran inmigrantes de origen europeo que habían quedado excluidos de la entrega de lotes de 100 hectáreas dispuestas por el Estado bajo la Ley de Inmigración y Colonización de 1876 o, también, provenientes de países limítrofes como Bolivia o Paraguay, que buscaban asentarse de manera provisoria para cumplir trabajos de temporada. Además, la denominación de "criollos" pasará a convertirse entre los indígenas en una distinción interétnica para aquellos sujetos "no indígenas".

7. Entre las más importantes: Napalpí y Zapallar, creadas en 1911 y 1930 respectivamente. En ambas se recuerdan las peores masacres cometidas sobre el pueblo Qom (Musante, 2009).

8. Desde la década de 1940, grupos religiosos de raíz protestante se introdujeron en las comunidades indígenas en Argentina. Desde sus inicios, la integración de los esquemas de liderazgo indígena a las estructuras de poder de las iglesias dio lugar al establecimiento de los pastores como nuevos mediadores culturales y sociopolíticos (Ceriani Cernadas, 2011).

9. Excede al alcance de este trabajo debatir sobre el sesgo paternalista de muchas de estas políticas y el acercamiento a los asuntos indígenas en términos de presencia y "tratamiento" del "problema", sin que se les considerara sujetos de derecho en tanto pueblos. Entendemos que fueron una serie de medidas impulsadas por el gobierno peronista que dieron respuesta a los reclamos y reivindicaciones de amplios sectores de la población argentina, cuya situación de postergación no había sido considerada por gobiernos precedentes. Según el sitio web, la empresa desarrolla 
proyectos ganaderos de investigación genética y producción de carne de alta calidad para exportación. Posee 20000 hectáreas destinadas a la agricultura, de las cuales 16000 se realizan bajo riego (Recuperado de: https://goo.gl/kpxqNp).

10. Según el sitio web, la empresa desarrolla proyectos ganaderos de investigación genética y producción de carne de alta calidad para exportación. Posee 20.000 hectáreas destinadas a la agricultura, de las cuales 16.000 se realizan bajo riego (Recuperado de: https://goo.gl/kpxqNp).

11. En la mayoría de los casos por problemas de actualización de las personerías jurídicas (modalidad bajo la cual se instrumenta el reconocimiento constitucional de las tierras indígenas), sucesión o división parcelaria de los terrenos donde viven las familias extendidas (Colla, 2015).

12. Con amparo en una investigación de la Facultad de Ciencias Exactas de la UBA, dirigida por la doctora María Alcira Trinelli, que detectó glifosato en el 56\% de los puntos de muestreo analizados en la zona, uno de los cuales fue la sala de salud de Campo Medina, donde se determinó contaminación por glifosato, arsénico y metales pesados.

13. En el paraje Campo Medina este número asciende a 1,40 ha por habitante mientras que en el paraje de Pampa Grande se registra un 0,75 ha por habitante.

14. Fuente: Informe (inédito) Relevamiento socio-productivo a comunidades campesinas indígenas. Federación Nacional Campesina, año 2014.

15. Notas de campo. Asamblea FNC, Pampa del Indio. Febrero, 2017.

16. La producción de algodón se vio perjudicada por las sequías que se registraron hasta 2012, la esporádica intervención estatal y la caída del precio del algodón. 13

\section{Bibliografía}

Balazote, A. (2012). Prologo. En Ricardo Orzi (Org.), Moneda social y mercados solidarios II: La moneda como lazo social. Buenos Aires: CiCCUS.

Bartra, A. (2011). Prólogo. En Hocsman, D., Estrategias territoriales, recampesinización y etnicidad en los Andes de Argentina (pp. 9-14). México, DF: Universidad Autónoma Metropolitana, Unidad Xochimilco.

Brodersohn, V., Valenzuela, C. y Slutzky, D. (2009). Dependencia interna y desarrollo. El caso del Chaco. Resistencia: Librería La paz.

Ceriani Cernadas, C. (2011). Evangelio, política y memoria en los Toba (qom) del Chaco argentino. Revista Nuevo Mundo Mundos Nuevos. Recuperado de: https://goo.gl/i4YuBp.

Checchi, Horacio. “Curioso modo de impartir justicia” publicado en Diario Página 12 el 12/04/06. Recuperado de: https://goo.gl/vRsFuT 
Colla, J. (2015). Aquí se respira lucha: prácticas políticas de los campesinos originarios Qom de Pampa del Indio (Chaco). (Tesis inédita de grado). Carrera de Lic. en Sociología, Facultad de Humanidades y ciencias, Universidad Nacional del Litoral, Santa Fe.

Cooperativa La Vaca (2015) “La Vida Fumigada”. Revista La Vaca, N 92, año 2015. Recuperado de: https://goo.gl/8PFoaG

Escobar, A. (2015). Territorios de diferencia: la ontología política de los "derechos al territorio". Cuadernos de Antropología Social, 41, 25-38.

Fernandes Mançano, Bernardo (2008). Entrando nos territórios do Território. En Paulino, E. \& Fabrini, J. (Org.), Campesinato e Território em disputas (pp.273-302). São Paulo: Expressão Popular. Recuperado de: https://goo.gl/7iTGY6

Fernández, A. \& Braunstein, J. (2001). Historias de Pampa del Indio. V Congreso Argentino de Americanistas. Buenos Aires: Sociedad Argentina de Americanistas.

Giarracca, N. y Teubal, M. (2005). El campo argentino en la encrucijada: Tierra, resistencia y ecos en la ciudad. Buenos Aires: Ed. Alianza.

Harvey, D. (2005). El “nuevo” imperialismo: acumulación por desposesión. Buenos Aires: Consejo Latinoamericano de Ciencias Sociales- CLACSO. Recuperado de: https://goo.gl/YhoLGP

Iñigo Carrera, V. (2009). Una población obrera sobrante en el Chaco argentino: su determinación y sus formas. Razón y Revolución, 19, 31-43.

Klipphan, A. y Enz, D. (2006). Tierras S.A. Crónicas de un país rematado. Buenos Aires: Ediciones Aguilar.

Machado Araoz, H. (2015). Conflictos socioambientales y disputas civilizatorias en América Latina: Entre el desarrollismo extractivista y el Buen Vivir. Revista Critica y Resistencias, I, 19-42.

Musante, M. (2009). Reducciones Indígenas. Un fantasma perdido entre archivos y relatos historiográfícos. Jornadas de sociología. Facultad de Ciencias Sociales. Buenos Aires: Universidad de Buenos Aires.

Porto Gonçalves, C. W. (2009). Territorialidades y lucha por el territorio en América Latina. Geografía de los movimientos sociales en América Latina. Venezuela: Ed.IVIC.

Porto Gonçalves, C.W. (2001). Da Geografia as Geografias: Um Mundo em busca de novas territorialidades En Ceceña, A. \& Sader, E. (comps), La guerra infinita: Hegemonía y terror mundial. Recuperado de: https://goo.gl/MsbDE9

Quijano, A. (2014). “Raza”, “etnia” y “nación” en Mariátegui: cuestiones abiertas En Quijano, A., Cuestiones y horizontes: de la dependencia histórico-estructural a la colonialidad/ descolonialidad del poder. Buenos Aires: Consejo Latinoamericano de Ciencias Sociales- CLACSO. Recuperado de: https://goo.gl/zPVhPS

Trinchero, H. (2000). Los dominios del demonio. Buenos Aires: Eudeba.

Valenzuela, C. \& Scavo, A. (2009). La trama territorial del algodón en el Chaco. Transformaciones 
recientes desde la perspectiva de los pequeños y medianos productores. Buenos Aires: Ed. La Colmena.

Vázquez, H. (2000). Procesos Identitarios y Exclusión Sociocultural. La cuestión indígena en Argentina. Buenos Aires: Editorial Biblos.

Wright, P. (2008). Ser-en-el-sueño. Crónicas de historia y vida toba. Buenos Aires: Editorial Biblos. Zavaleta Mercado, R. (1986). Lo nacional-popular en Bolivia. México: Editorial Siglo XXI. 